\title{
STUDENT PERCEPTIONS OF THE IMPACT OF WEB-BASED HOMEWORK ON COURSE INTERACTION AND LEARNING IN INTRODUCTORY ACCOUNTING
}

\author{
Christopher G. Jones, California State University, Northridge, christopher.jones@csun.edu
}

\begin{abstract}
According to Laurillard's Conversational Framework, teaching and learning are a dialogic activity in which the student attempts to re-construct the teacher's mental model of the material. An essential part of that dialog between teacher and student is the feedback teachers provide to help students adapt their understanding of the concepts presented. Providing this individualized feedback is time consuming and often beyond the resources available to faculty. To address the need for a more efficient and effective approach to offering feedback, textbook publishers, commercial vendors, and the open source community have developed web-based homework (WBH) systems that provide automated grading. This paper examines the use of a commercial web application (WileyPLUS) to automate grading of multi-part accounting exercises and problems in an introductory accounting course for business majors. A survey research methodology was used. Results indicate that web-based homework systems enhance learning but do not increase perceived course interaction levels. Immediate feedback and allowing for multiple attempts encourages practice with the material. Students are mixed on whether restructuring textbook problems to operationalize online grading adequately prepares them for exams.
\end{abstract}

Keywords: accounting education, automated grading, educational technology, e-learning, online assessment, web-based homework, WileyPLUS

\section{INTRODUCTION}

\section{The Conversational Framework and Automated Grading}

According to Diana Laurillard [10] academic knowledge is a second-order phenomenon. Academic knowledge represents the teacher's experience of the world and is often encoded in a special vocabulary and formal notations. To acquire such academic knowledge, the learner is invited to participate in a dialogue. "Through debate and discussion with the teacher, or at least vicarious experience of it in tutorials, the student can begin to see how the specialist language works, how the discourse proceeds in a particular discipline” [12, p. 172].

Teaching and learning, then, become a dialogic activity. Laurillard [10] has formalized her learning theory into a model she refers to at the "Conversational Framework" (See Figure 1). Under this framework, the learning process involves an iterative exchange between teacher and student at two distinct levels. At the one level, referred to as "discursive activities," the teacher presents the conceptual knowledge-ideas or theory to be learned. The student engages with the stated content through question and answer. As the interplay and communication continues, the teacher clarifies or elaborates on the material.

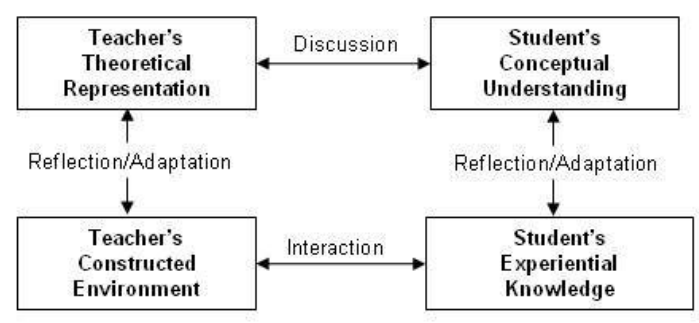

Figure 1 Laurillard's Conversational Framework for the learning process

At the second level, characterized by "interactive activities", the student puts the theory into practice through experiential tasks such as exercises, laboratory experiments, or even field trips. As teachers monitor students' experiential progression, they provide feedback, enabling students to improve their understanding of the conceptual knowledge. At the same time, students are expected to "reflect" on their experiences and "adapt" their actions, as a way of bridging theory and practice. In Laurillard's model of instruction, "interaction" is central to "deep" learning [8].

Laurillard's Conversational Framework, however, was a means to end. She developed the model as an evaluative tool for examining how various applications of technology measure up to the requirement of a "more progressive" teaching model 
$[13,11]$. As part of that model, she developed an education media framework composed of five media forms. The five forms, each of which supports a different type of learning experience are (a) narrative, (b) interactive, (c) communicative, (d) adaptive, and (e) productive. The fourth media form, Adaptive, refers to computer-based devices capable of changing state in response to user action. This is usually accomplished through some form of modeling or feedback mechanism. Adaptive media support (a) "experimenting”, (b) "practicing”, and (c) "clarifying internal relations". Typical resources and technologies include simulation, virtual environments, tutorial programs and simulations, educational games, labs, and field trips. Automated grading of homework assignments, for example, is a form of adaptive media for supporting the learning process. Web-based homework systems (WBH), the subject of this article, facilitate interaction by helping students move from an initial conceptual understanding to experiential knowledge that more closely approximates the teacher's mental model of the course material.

\section{Computerized Grading Of Accounting Homework}

According to market research [19] conducted by John Wiley and Sons, Inc. in Spring 2006, 82\% of students found the immediate feedback provided by automated assignment scoring to be either "very helpful" or "somewhat helpful". The survey was conducted online with students from over ten different disciplines. Just under 1000 responses were received with $53.8 \%$ of the respondents from Accounting. Seventy-four percent of students in the survey reported that the WileyPLUS course management system with automated grading "helped them get a better grade in their courses” [19, p. 2].

Granted the Wiley survey research is suspect, having been based on a convenience sample and sponsored by the publisher as part of on-going market testing. Nevertheless, the data does confirm a substantial buy-in by accounting educators to use this type of feedback software to support accounting instruction. Faculty in institutions without budgets for graders find off-loading of grading to automated scoring software a real time saver. Publishers claim that students find the immediate feedback provided by computerized grading of accounting assignments helpful and a factor in achieving a better course grade. Students like the convenience of being able to check the right answers without having to meet with the professor during office hours or schedule time to attend Accounting tutoring sessions.
WileyPLUS is joined by other commercial grading software products. Prentice-Hall (PH) complements its accounting texts with PH Grade Assist. This product supports business, computer science, and engineering disciplines [16]. McGraw-Hill [14] offers Homework Manager/Homework Manager Plus for business and accounting. Cengage Learning [4] (formerly Thomson Publishing) provides CengageNOW for automated grading and course management in accounting and business disciplines.

Boyce [2] and Bryant and Hunton [3] reported on the use of educational technology in support of accounting instruction. Boyce [2] examined productivity, drill-and-practice, modeling and simulation, Internet and web application software. With regards to desktop drill-and-practice software, he concluded that such software "can enable more effective learning in areas that can be automated, making the mastery of the basic procedural skills less tedious" (p.197). Bryant and Hunton [3] categorized educational technologies into three general groups computer-based learning, distance learning and hypermedia, and multimedia. Using these groupings as a framework for a category by category literature review, Bryant and Hunton examined one study by Clariana, Ross, and Morrison [6] that explored computer-aided instruction with drill-and-practice software. Results showed significant benefits of feedback over no-feedback, with Answer Until Correct more advantageous and delayed feedback less so.

To date, little research has been conducted on the role of web-based homework systems in accounting instruction. Does, for instance, WBH support the feedback-reflection-adaptation phase of the learning process in Laurillard's teaching model? This paper examines the impact of WBH on course interaction and student learning in an introductory accounting course. Specifically, the answers to the following research questions were sought:

1. If homework is not collected and graded, would students spend less time practicing course concepts?

2. Do students prefer paper-based homework with no individual feedback over web-based homework with individual feedback?

3. Where do students access the web to complete online assignments?

4. How many hours per week do students spend on web-based exercises?

5. Do students believe technical issues with computers, the web, or the WBH system affect their course performance? 
6. Do students perceive automated homework grading as a form of course interactivity?

7. Do students believe web-based homework enhances learning?

8. Do multiple attempts and immediate feedback increase motivation to practice with course material?

9. What is the ideal number of attempts students should be allowed before assignment submission?

10. Are exercise hints helpful in clarifying what is required?

11. What is the ideal number of attempts before revealing exercise hints?

12. Are the links to the electronic text and online animations helpful?

13. Do students believe the breakdown of exercises into automatically gradable components adequately prepares them for paper-based problems found on quizzes and in exams?

14. What are the primary advantages of using a WBH?

15. What are the primary disadvantages?

16. Is there a relationship between gender, age, major, or Internet comfort level and student perceptions of the impact of homework format, technical difficulties, interactivity, learning, motivation, hints, e-text access, and exam preparation?

\section{LITERATURE REVIEW}

The application of technology to homework finds its genesis in early computer-aided instructional efforts, such as PLATO elementary accounting modules [15]. With the advent of personal computers, networks, and web browsers homework submission and grading platforms migrated to the Internet [1]. Early candidates for web-based homework were mathematics, the physical sciences, accounting, and business.

\section{Web-based Homework Systems}

WBH may be a self-contained web application or modules in a web-enabled course management system. Bonham et al. [1] define a web-based homework system as follows:

In a typical Web-based homework system, students log on using a password through the Internet to a central Web sever, select one or more assignments, and receive those exercises... In many cases the numerical exercises are randomized, so each student assignment has a unique set of numbers.
Depending on the system and the individual, students could work through the exercises while seated at the computer or they may obtain a printed copy of the exercise to work out elsewhere. After determining the answers, students will then submit their solution, which is most commonly a numerical result or one option from a multiple choice list, but could also consist of selecting multiples options in a list, entering a symbolic (algebraic) answer, typing in a word or short essay, or uploading a file. In most cases, the computer immediately evaluates the answers, gives the student some level of feedback, and may allow reworking and resubmission of the assignment depending on how the instructor has set options. The instructor is able to handle administrative details, create assignments and questions, and review or download student scores and responses. Some systems have additional features such as chat rooms, instructor notes, calendars, and other features (p. 1053).

Several empirical studies have been performed comparing web-based and paper-based homework as it affects student performance. In a pairedcomparison quasi-experimental design of large lecture sections of calculus and algebra-based physics courses at a large public university, Bonham et al. [1] found no significant difference in exam scores between students using $\mathrm{WBH}$ and those using paper. Students in the WBH groups used WebAssign for homework distribution, collection, and grading. Other key findings included (a) most students attempted assignments two to three times, and (b) students uncomfortable with technology were more likely to be intimidated or confused by the task at hand.

For 19 college-algebra classes using WeBWork to deliver, collect, and grade college algebra assignments, Hauk and Segalla [9] found no significant difference between $\mathrm{WBH}$ and paper in pre- and post-test performance by homework group, ethnicity, or gender. In both the Bonham [1] and Hauk [9] studies, the authors concluded that WBH is at least as effective as paper and pencil homework.

Dufrense, Mestre, Hart, and Rath (2002), on the other hand, found that WBH led to higher overall exam performance. The Dufrense et al. study was conducted using Online Web-based learning (OWL) at a large U.S. public university located in the Northeast. Students in large enrollment introductory 
physics courses using OWL to submit assignments and receive homework feedback, scored significantly higher on course exams than students in the paperand-pencil treatment group

Tang and Titus [18] found that using WebAssign with college calculus and physics students to deliver collect and grade homework: (a) increased the level of interaction with faculty and peers, (b) increased the time spent on coursework outside the classroom, and (c) enabled faculty to revise course focus based on immediacy of student feedback.

\section{Advantages and Disadvantages of WBH}

Proponents of $\mathrm{WBH}$ argue that students prefer the web over the paper-and-pencil approach to homework for a variety of reasons:

1. Provides instant feedback

2. Allows for multiple submissions

3. Encourages spending more time with the material through increased interaction

4. Facilitates learning from one's mistakes

5. Affords anytime, anywhere access

6. Ensures consistent grading

Instructors like WBH systems because they reduce time spent grading [7, 18]. Web-based homework systems, however, are not without their detractors. Opponents claim that (a) allowing multiple submissions encourages a trial and error approach to assignment completion, (b) feedback is not as detailed as paper and pencil grading, (c) automated grading is impersonal, (d) discomfort with technology or technology difficulties hampers learning, (e) simple syntax errors (such as misplacing a decimal) result in wrong answers, and (f) corrective yes/no feedback hinders metacognitive development [17].

\section{PROCEDURES AND METHODS}

\section{WileyPLUS at CSUN}

California State University, Northridge (CSUN) is a large urban public university located in the greater Los Angeles metropolitan area. The College of Business and Economics is home to 6000 business students. Every semester between 400 and 500 students enroll in ACCT 220 Introduction to Financial Reporting. This course is a requirement for all business and accounting students and a service course for construction management and health administration. Except for a few large lecture sections (120 seats), most sections are between 35 and 50 students. CSUN is AACSB-accredited with over $80 \%$ of all accounting instruction provided by full-time faculty.

The introductory accounting course is coordinated by a lead instructor. All sections use the same text. Each faculty member is responsible for developing his/her own assignments and exams. Most Accounting faculty require students to submit homework using the web. WileyPLUS from John Wiley \& Sons Publishing is the course homework platform. A few instructors do not use the web but rather assign paper and pencil homework, collect it for check in only, and review solutions in class.

During Spring 2008, a survey of student perceptions of web-based homework was administered in class to three sections of the author's introductory accounting course. For the classes surveyed, WileyPLUS was used to deliver, submit, and grade the exercise and problem portion of the weekly assignments. WebCT, a course management system, was used for all course communication and to display the grade spreadsheet.

Students generally have one week from the completion of the chapter lecture to submit the webbased homework. Assignments are due at the beginning of class. The WileyPLUS assignment electronic dropbox closes just after the class starts to discourage students from missing class just to complete an assignment. Each assignment is comprised of two portions (1) the WileyPLUS exercises and problems, and (2) free-form answers to end of chapter questions on key concepts. The freeform answers are required to be submitted on paper. The paper and pencil portion of the assignments are collected in class on the same due date as the WileyPLUS portion is to be submitted. The paper portion of the assignment is checked in for credit; no individual feedback is provided

When working with WileyPLUS, students receive individual feedback on the completed portions of a multi-part accounting exercise each time they click the < Submit Answer $>$ button. After three attempts, students receive a publisher-provided hint. On the fifth try, all parts of the exercise are graded and the score recorded. Students are, then, given the option to view the solution. Students may, also, view an online gradebook in WileyPLUS to see the total score for the web-portion of the assignment along with class averages.

Once a week the instructor imports the WileyPLUS grades into a comprehensive MS Excel spreadsheet that combines the score on the web-portion of the 
assignment with the paper portion. The spreadsheet details the high, low, and average score for each weekly assignment. Grade spreadsheets for each course section are uploaded weekly to WebCT and made available to students through a link on the class homepage

Figure 2 shows a screen shot of a partially completed chapter exercise. The chapter problems displayed in WileyPLUS closely parallel the problems in the text but have been modified to facilitate automated grading.

E9-5

Phill Co. has delivery equipment that cost $\$ 54,000$ and has been depreciated $\$ 20,000$.

Record entries for the disposal under the following assumptions. (Round answers to 0 decimal places.

It was scrapped as having no value.

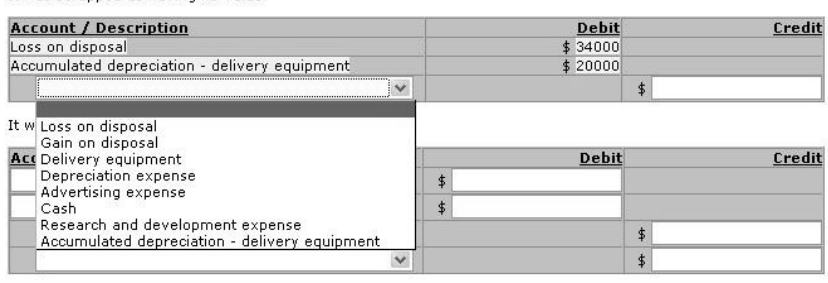

Question Attempts: 0 of 5 used

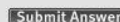

Figure 2. Screen shot of partially completed exercise in WileyPLUS

The same exercise from the text, reads as follows:

E9-5

Phill Co. has delivery equipment that cost

$\$ 54,000$ and has been depreciated

$\$ 20,000$.

Instructions

Records entries for the disposal under the following assumptions.

(a) It was scrapped as having no value.

(b) It was sold for $\$ 37,000$

(c) It was sold for $\$ 18,000$

As can be seen, automated grading requires the addition of a user-interface to facilitate input. For exercise 9-5, WileyPLUS provides string text boxes, numeric text boxes, and drop-down lists.

\section{FINDINGS AND DISCUSSION}

Using the specific research questions detailed earlier, relevant literature, and survey questions from Tang and Titus [18], a survey instrument was developed to assess the impact of web-based homework on introductory accounting students. During Spring 2008, a survey of student perceptions of web-based homework was administered in class to three sections of the author's introductory accounting. No incentive was offered for participation. Eighty-three responses were received yielding a response rate of $74.8 \%$.

\section{Demographics}

A slightly higher percentage of respondents $(N=83)$ were male $(54.2 \%)$. Ninety-five percent of the respondents were between 18 and 25 years old with a little over $70 \%$ between 18 and 21 years. Marketing (21.7\%), Pre-Accountancy (20.5\%), and Business Administration (16.9\%) majors accounted for the majority of students. Over $75 \%$ of respondents felt very $(42.2 \%)$ or somewhat $(33.7 \%)$ comfortable with using the Internet to do homework. About $10 \%$, however, were not comfortable with the Internet for coursework.

\section{Research Question 1: No Homework Means Less Study}

Over seventy percent of students (strongly agree $36.1 \%$; agree - $34.9 \%$ ) indicated that they would spend less time studying if homework was not collected. This supports Tang and Titus' findings [18] in which 58\% of physics and calculus students claimed they would study less if homework was not required. Tang and Titus [18] interpret this result as an endorsement for web-based homework because it "motivated them [students] to spend more time on homework and studying." Whether use of a WBH is, in fact, motivational cannot be inferred from the response to this survey question. What is clear is that not requiring homework results in an intention to spend less time on task.

\section{Research Question 2: Paper-based vs. Web-based Homework}

Given the option to submit exercises and problems either through the web or on paper, students overwhelmingly preferred a WBH system (73.2 \%) that provides immediate feedback. The remaining respondents (26.8\%) indicated they would rather submit exercises on paper and have them checked in for credit; paper-based exercises would not be individually graded. Under the WBH option students receive partial credit for portions of the assignment that are correct. Solutions are made available online to students once the assignment is submitted. In the paper-based option, students receive full credit for turning in the assignment whether the answers are correct or not. Solutions are reviewed in class once the homework is returned. The two options represent how homework is currently handled in the introductory accounting course. 
Faculty using WileyPLUS allow up to five attempts for each online submission. Feedback is instantaneous and is provided after each attempt. Some faculty review solutions briefly in class once the due date is past. Others do not take the time to go over solutions in class. Faculty that do not use WileyPLUS, require all accounting assignments be submitted on paper. Assignments are checked in for credit. The solution to the assignment is discussed in class once the homework is returned to the students.

All three sections of introductory accounting completing the survey are currently using the webbased option to submit homework. Student response to the paper vs. web survey question is, no doubt, influenced by present practice and more than likely reflects treatment bias. Nevertheless, results confirm prior research on homework grading options. In the Tang and Titus [18] survey, Physics and Calculus students were asked to select between the following two options:

- Paper homework - submit homework on paper once per week, have it graded by hand (just right or wrong indicated with no partial credit), and returned within two days.

- Online homework - Submit homework via WebAssign with ten submissions and right/wrong feedback.

Over $90 \%$ of respondents preferred the online homework option. Tang and Titus [18] speculate that students prefer online due to features such as "multiple submissions and immediate feedback."

\section{Research Question 3: Where Accessed}

The vast majority of students (84.1\%) complete webbased homework assignments at home. Only 12.2\% of students complete assignments on the university campus. A few students do their homework at an Internet café $(1.2 \%)$, at work(1.2\%), or in a public library(1.2\%).

These results contrast with the 2002 Tang survey [18] in which $48 \%$ of students completed web-based assignments at school and another $45 \%$ at home. The migration to the home from school for web access may be a function of respondent demographics (Greensboro, NC in the Tang study [18]) or a trend toward broadband penetration in home markets. Regardless, the survey response indicates that webaccessibility is no longer a hurdle to online assessment.

\section{Research Question 4: Time on Task}

Most students (49.4\%) spend two to four hours per week completing web-based assignments. This is over and above the time spent on any paper-based homework required for the class. In the introductory accounting sections surveyed, students are required to submit answers to selected chapter questions on paper. A little over twenty percent of students spend between zero and two hours (21.7\%) and between four and six hours (21.7\%) completing the online portion of the class assignments. A handful of students reported spending more than six hours per week on the web portion of the assignments. In the Tang study [18], students completed their entire assignment online. Thirty-three percent of students spent four to six hours; $32 \%$ from two to four hours. Adding in the time for paper-based homework and chapter reading would, more than likely, bring the results of this survey in line with the Tang study [18]. It would appear the survey results mirror Tang and Titus' [18] conclusion that time on task for a three hour course is somewhat below the weekly requirement stated in the course syllabus of six to nine hours per week outside of class.

\section{Research Question 5: Effects of Technical Difficulties}

Most students (67.5\%) reported that technical difficulties did not affect their course performance, with 19.3\% neutral on the impact of technical issues. A little over $13 \%$ of students indicated that technical problems with the web-based homework system were a concern. Of the 11 respondents claiming technical difficulties, only one reported discomfort with using the web for homework. This would indicate that, at a minimum, $12 \%$ of respondents accustomed to or ambivalent to using the web are experiencing enough computer, network, or WBH system trouble to generate concern over the impact on course grades.

During the semester there has been at least one outage of the WBH server. Students have been reassured that any outage will not affect their grade. Due dates were (and will be) extended as needed. Regardless, student concern is legitimate and needs to be addressed. When a little over 1 in 10 students worries about the impact of technology on course performance there is cause for additional user training and the need to make technical support more accessible.

Survey results are similar to those in the Tang study [18]. In that study $55 \%$ of students were not concerned about technical difficulties; 22\% were 
ambivalent. Twenty-three percent of students expressed concern about the impact of technical issues on their grade. Calculus students were more concerned than Physics students. A greater proportion of Calculus students reported trouble with how equations were graded for symbolic mode questions. These types of questions are rare in an introductory accounting course which could account for why fewer students (13\%) voiced concerns over technical issues than in the reference survey (23\%).

\section{Research Question 6: Course Interaction}

As discussed earlier, web-based homework systems are an adaptive media that supports the interaction required for deep learning to occur in accordance with Laurillard's Conversational Framework. When asked if WBH increases the level of interaction with the professor in or outside of class, there was no clear agreement one way or the other. Over forty percent (44.6\%) of respondents viewed the WBH as neither increasing nor decreasing the interaction levels. A little less than twenty percent (19.3\%) agreed that use of the WBH increased interaction while $36.2 \%$ disagreed. No doubt, use of a WBH increases the computer-student interaction by providing multiple feedback points through assignment completion and submission. But for the most part, students do not perceive use of the WBH as increasing the studentteacher interaction; that is, increased computerstudent interaction does not translate into an increase in student-teacher interaction. Computer-student interaction is by its nature interactive but because such interaction does not directly emanate from the teacher, students do not attribute it to the teacher.

In the Tang study [18], results were split. Seventyfour percent of students in the small-section Calculus course responded that use of the WBH resulted in increased faculty contact. Only 38\% of students in the large-section Physics course felt they had had increased faculty contact. Tang [18] speculates that the difference is due primarily to class size and the type of questions assigned.

\section{Research Question 7: Enhanced Learning}

More than 70 percent $(71.1 \%)$ of students reported that using WileyPLUS enhanced their learning of the course content. Only 12\% disagreed. Just under seventeen percent $(16.9 \%)$ responded that they neither agreed nor disagreed. Survey results corroborate Tang and Titus' findings [18] that 64\% of WebAssign users found the WBH enhanced their learning. Fourteen percent of respondents disagreed while $21 \%$ were neutral. It would appear students, regardless of the platform (WebAssign vs. WileyPLUS), perceive web-based homework systems as a valuable education tool for improving material mastery.

\section{Research Question 8: Motivating Practice}

Over sixty percent (66.3\%) of students reported that the WBH features of immediate feedback and multiple attempts encourages practicing with the course material. A little over 20 percent (21.7\%) were neutral. Twelve percent of respondents did not feel the WBH promoted practice. Research shows that time on task is a key factor in improving student performance [5]. Having pedagogical tools that encourage students to spend more time with the material leads to the possibility of increased learning. Survey results show that WBHs can be used to motivate studying.

\section{Research Question 9: Ideal Number of Attempts}

Students were asked to indicate what they felt would be the ideal number of attempts before a web-based assignment should be submitted for final grading. Just over fifty percent (50.6\%) preferred five attempts before grading. All respondents are currently using WileyPLUS to submit assignments. Five attempts are allowed before the answer is recorded. Survey results mirror current course configuration and usage; this could reflect treatment bias. Some research indicates that students using WBH systems generally attempt the exercise three times before submitting for final grading [1]. It would be interesting to analyze actual submission statistics to determine number of attempts before submission. Students may prefer more attempts than they actually use.

\section{Research Questions 10 and 11: Helpfulness of Hints}

Only forty-three percent (43.4\%) of respondents found the hints provided by the WBH to be helpful. In the current course configuration of the $\mathrm{WBH}$, hints are revealed after the third attempt to complete the exercise or problem. Hints are usually check figures (e.g. Net Income $\$ 1,200,045 ;$ LIFO Inventory $\$ 35,690)$. These hints are also printed in the margins in the hardback version of the text. A little over twenty-five percent $(25.3 \%)$ of respondents were neutral on the value of the hints. Just over thirty percent (31.4\%) did not agree that the hints were actually helpful. Hints appear to be an area for improvement for WileyPLUS. 
When asked when hints should be revealed, fortyfive percent (44.6) of students preferred to see hints after the second attempt. Forty-two (42.2\%) indicated they would like to see hints after the third attempt at the problem. Currently, the introductory accounting course is configured to reveal the hint after the third attempt; five attempts are possible. Based on survey results, it would appear students prefer to see hints a little sooner than current practice.

\section{Research Question 12: Helpfulness of Links}

Many WBHs, including WileyPLUS, provide hyperlinks to the point in an electronic version of the text where the concepts being assessed are discussed by the textbook author(s). In addition, some WBHs provide hyperlinks to online animations that review concepts being tested. Thirty-nine (38.6\%) percent of students agreed that these links were helpful. Thirtyseven (37.3\%) percent were neutral. Twenty-four (24.1\%) percent of respondents did not find the links to be helpful. Survey results indicate students do not find the links to be as helpful as the hints. Like hint support, link support in WileyPLUS requires improvement. It is possible students perceive the granularity of links as too high to be useful. Links generally point students to the starting point in the chapter where the discussion begins for the learning objective being assessed. Students may prefer direct links to example problems instead. Further research is required to determine the reasons for hint and link dissatisfaction.

\section{Research Question 13: Restructured Exercises to Facilitate Automated Grading}

Some researchers claim that the use of WBH systems for homework in lieu of paper hinders metacognitive development [17]. There is something about writing out the answer to a problem on a blank piece of paper that forces students to master journalizing entries or accounting report formats. To facilitate automated grading, WBHs that support accounting instruction, break down problems into small pieces with multiple parts. As discussed earlier, these parts then are coded to allow machine-based grading. Drop-down lists are provided and populated with possible answers. This exercise scaffolding to force right/wrong evaluation does not always match the format and layout of problems students are asked to complete on quizzes and exams. When asked if the WileyPLUS breakdown of problems for grading adequately prepared students for quizzes and exams, the majority (56.5\%) of students agreed. A little over twenty percent $(22.9 \%)$ were neutral. Twenty-one percent (21.4\%) disagreed, with eleven percent (10.8) disagreeing strongly. While half of the students find modification of the exercises from text-to-WBH format affords adequate test preparation, the other half does not find the revamped structure adequately prepares them for the kinds of questions found on course quizzes and exams. As one student commented, "It is also frustrating when we take a test because there is [sic] no drop down windows."

\section{Research Questions 14 and 15: Web-based Homework Advantages and Disadvantages}

In response to one of two open-ended questions in the survey, students identified the advantages to using WileyPLUS for submitting and grading homework. Responses were fairly consistent. To facilitate analysis of the free form answers, responses were grouped based on similarities and frequencies tabulated. The three primary advantages were: (1) provides immediate feedback $(36.4 \%)$, (2) is paperless and saves trees (eco-friendly) (12.1\%), and (3) allows multiple attempts (7.5\%). Other frequently mentioned advantages include speed, convenience, partial credit on grading, and encourages practice and further study.

With regards to the disadvantages of using a WBH, there was less of a consensus among students. Primary disadvantages were: (1) takes too long (8.9\%); (2) grading is too strict with no allowance for rounding and formatting of percents (7.9\%); (3) requires a computer $(7.9 \%)$; requires an Internet connection (7.9\%); and subject to technical difficulties (6.4\%). Less frequently mentioned disadvantages included the inability to review work once submitted, solutions not being reviewed in class, unclear exercises and problems, encourages guessing rather than learning, fear that submission will be lost before it is recorded, and doesn't help with exams.

\section{Research Question 16: Influence of Selected Demographics on Student Perceptions}

As part of the survey, student demographics were collected for gender, age, major, and Internet comfort level. One-way ANOVA was used to test the impact of the first three demographics. No statistically significant differences were found between gender, age, or major on homework format preference; effect of technical difficulty on course performance; perceived interaction levels, learning levels, and motivation; value of hints; value of e-text access; and, adequacy of preparation for exams.

Pearson $r$ was used to examine the influence of Internet comfort level on homework format, technical 
difficulties, interactivity, learning, motivation, hints, e-text access, and exam preparation. Comfort level is negatively correlated with the effect of technical difficulty on course performance (Pearson $r(\mathrm{~N}=80)$ $=-0.284, p=.011)$. Students with Internet discomfort are more likely to agree that technical difficulties have significantly affected their course performance. Students with low Internet comfort levels are less likely to perceive increased faculty interaction than students with high comfort levels (Pearson $r(\mathrm{~N}=80)$ $=0.242, \mathrm{p}=.030)$. The same pattern holds for increased learning and practice encouragement. Students with Internet discomfort are more likely to disagree that WileyPLUS enhances learning (Pearson $r(\mathrm{~N}=80)=0.554, \mathrm{p}=.000)$ or encourages practice with the course material (Pearson $r(\mathrm{~N}=80)=0.312$, $\mathrm{p}=.005$ ). Finally, students with low Internet comfort are more likely to prefer paper-based homework over web-based homework (Pearson $r(\mathrm{~N}=80)=0.388$, p $=.000)$.

\section{LIMITATIONS OF THE STUDY}

Although the $75 \%$ response rate was good for a convenience sample, the dataset $(\mathrm{N}=83)$ is still somewhat small. To address the low sample size, additional survey research is currently in progress. Several additional introductory accounting sections will be surveyed. Plans are to tabulate these responses and combine them with the first survey dataset. A revised analysis will then be conducted.

Because respondents were not randomly selected, results are not generalizable. Our findings might not be representative of students at other institutions of higher education nor of students using web-based homework systems other than WileyPLUS. Notwithstanding these limitations, we believe students participating in the survey provided valuable insight into web-based homework practices and issues.

\section{CONCLUSION}

Web-based homework systems or modules provide resource-constrained colleges and universities with the option of providing cost-effective individualized feedback to students on assignment exercises and problems. As an Adaptive education medium supporting what Laurillard refers to as the "interactive activities" of the conversational framework, WBH is on par with pencil-and-paper homework.

When given the option of ungraded paper-based homework versus WBH with individualized grading, students prefer web-based homework systems. Most introductory accounting students have Internet access and complete their assignments at home. On average students spend two to four hours per week doing internet assignments for class.

While technical difficulties are still an issue for some students, most students do not believe technical concerns affect their course performance. Students do agree that WBHs enhance learning but they do not agree that WBHs increase the level of course interaction. Instant feedback and allowing for multiple attempts encourages students to practice with the material. Most students prefer to have five attempts before their assignment is recorded. Hints are perceived as somewhat helpful, as are the links to the electronic version of the text. Hints and links are an area for improvement in WBH systems. This appears to be more a function of hint content and link granularity than a weakness of the systems themselves. About half of the students believe the restructuring of problems to allow for electronic grading gives them enough exposure to the material to adequately prepare them for exams. The other half is less positive, with some students complaining that the restructured problems are too dissimilar from quiz and exam problems to be of much help.

Students appreciate the immediate feedback, paperlessness, and “do-over features” of WBHs. As one student commented in the open-ended portion of the survey "More chances of getting the problem right helps you understand the material.” The biggest concern with WBHs is technical - usage requires a computer and an internet connection and is subject to outages. Some end-of-chapter problems are long, requiring lengthy periods in front of the screen.

Of the four demographics collected for the survey, only comfort level with the Internet proved to have statistical significance. Students who are uncomfortable using the Internet for homework tend to prefer paper instead. They tend to perceive more technical difficulties, lower interaction levels, lower learning, and less encouragement to practice. Fortunately, the percentage of students citing discomfort with the Internet is low (9.6\%). Faculty should be sensitive to the impact technophobia has on student performance and take a proactive approach to these "reluctant users." At a minimum, students should be reassured that server outages will not affect grades. Access to campus and vendor-provided technical support should be demonstrated early on in the course. 


\section{REFERENCES}

1. Bonham, S., Deardorff, D, \& Beichner, R. (2003). Comparison of student performance using web and paper-based homework in college-level physics. Journal of Research in Science Teaching, 40(10), 1050-1071.

2. Boyce, G. (1999). Computer-assisted teaching and learning in accounting: Pedagogy or product? Journal of Accounting Education, 17(2/3), 191-220.

3. Bryant, S. \& Hunton, J. (2000). The use of technology in the delivery of instruction: Implications for accounting educators and education researchers. Issues in Accounting Education 15(1), 129-162.

4. Cengage Learning. (2008). Just what you need to know and do NOW. Retrieved April 1, 2008 from http://west.ilrn.com/ilrn/

5. Chickering, A. \& Gamson, Z. (1987). Seven principles of good practice in undergraduate education. American Association for Higher Education Bulletin, 39, 3-7.

6. Clariana, R., Ross, S. , \& Morrison, G. (1991). The effects of different feedback strategies using computer-adminstered multiple-choice questions as instruction. Educational Technology Research and Development, 39 (2), 5-17.

7. Dufresne, R., Mestre, J, Hart, D., and Rath, K. (2002). The effect of web-based homework on test performance in large enrollment introductory physics courses. Journal of Computers in Mathematics and Science Teaching, 21(3), 229251.

8. Hannon, P. A., Umble, K. E., Alexander, L., Francisco, D., Steckler, A., Tudor G., \& Upshaw, V. (2002). Gagne and Laurillard's models of instruction applied to distance education: A theoretically driven evaluation of an online curriculum in public health. International Review of Research in Open and Distance Learning, 3(2). Retrieved January 7, 2008, from http://www.irrodl.org/index.php/irrodl/article/vie w/105/558

9. Hauk, S. \& Segalla, A. (2005). Student perceptions of the web-based homework program WeBWorK in moderate enrollment college algebra classes. Journal of Computers in Mathematics and Science Teaching, 24(3), 229253.

10. Laurillard, D. (2002a). Rethinking university teaching: A conversational framework for the effective use of learning technologies (2nd ed). London, UK: Routledge.
11. Laurillard, D. (1996, April 30). The changing university. Paper presented at the Instructional Technology Forum. Retrieved January 25, 2003, from http://www.listserv.uga.edu/cgibin/wa?A2=ind9604\&L=itforum\&P=R6791

12. Laurillard, D. (1997). Learning formal representations through multimedia. In Entwistle, N., Hounsell, D., \& Marton, F. (Eds.) The experience of learning, (2nd ed.). Edinburgh, Scotland: Scottish Academic Press.

13. Laurillard, D. (2002b). Rethinking teaching for the knowledge society. EDUCAUSE Reviews, 37(1), 16-25.

14. McGraw-Hill Irwin. (2008). Homework Manager. Retrieved April 1, 2008 from http://www.mhhe.com/business/homework/

15. McKeown, J. (1976). Computer-assisted instruction for elementary accounting. The Accounting Review, 51(1), 123-130.

16. Nail, G. H. (2006). PH Grade Assist: Homework in the twenty-first century. Proceedings of the 2006 ASEE Southeast Section Conference.

17. Pascarella, A. (2004). The influence of webbased homework on quantitative problemsolving in a university physics class. Proceedings of the NARST 2004 Annual Meeting, April 1-3, 2004.

18. Tang, G. and Titus, A. (2002). Increasing students' time on task in calculus and general physics courses through WebAssign. Proceedings of the 2002 American Society for Engineering Education Annual Conference and Exposition.

19. Ward, V. and Clayton, J. (2006). Using a commercially devised, electronic, teaching and learning environment. University of Portsmouth Learning and Teaching Conference 2006. Retrieved January 7, 2008, from http://media.wiley.com/assets/1148/92/practice.p df 